\title{
Handgrip strength and body mass index among adolescents in Northern Nigeria
}

\author{
Yahaya Abdullahi1* ${ }^{*}$ Talatu Audu², Daniel Ter Goon³ \\ 'Department of Human Kinetics and Health Education, Faculty of Education, Ahmadu Bello University, Zaria, Nigeria, \\ ${ }^{2}$ Department of Physical and Health Education, Federal College of Education, Zaria, Nigeria, ${ }^{3}$ Department of Public Health, \\ University of Fort Hare, East London Campus, South Africa
}

\begin{abstract}
Introduction: Normative data on handgrip strength (HGS) and body mass index (BMI) are scarce among adolescents in the Nigerian context. The aims of this study were to evaluate patterns of HGS in relation to gender and age in Nigerian adolescents and its correlation with BMI.

Methods: This cross-sectional study involved 1966 participants (1275 males) and (691 females) aged 12-20 years in Northern Nigeria. Body mass and height were measured. HGS was assessed using a dynamometer.
\end{abstract}

Results: The right HGS (RHGS) was significantly higher than the left HGS (LHGS) $(t=21.337, p<0.05)$. There were significant age differences in the RHGS and the LHGS $(p<0.05)$; however, no significant difference occurs at 12-14 years. Males participants aged 16-20 years had significantly higher RHGS values than females of the same age $(p<0.0038)$. Conversely, males aged $15-20$ years had significantly higher LHGS values than females of the same age $(p<0.0038)$. There was a significant interaction between gender and age for the RHGS $(F=72.2, p<0.05)$ and the LHGS $(F=92.1, p<0.05)$. There was a significant correlation between the BMI and RHGS $(r=0.480, p<0.01)$ and the LHGS $(r=0.465, p<0.01)$.

Conclusion: There are gender and age difference in the HGS of Nigerian adolescents, with the dominance of the RHGS in both genders. HGS correlated with BMI. This normative data on HGS may serve as baseline data for future comparative studies assessing HGS among the adolescent population in Nigeria.

Keywords: Adolescents; handgrip strength; body mass index

\section{INTRODUCTION}

The hand is the most dynamic and interactive part of the upper limb in humans (1). The hands have the ability to perform several tasks such as

\footnotetext{
*Corresponding author: Yahaya Abdullahi, Faculty of Education, Department of Human Kinetics and Health Education, Ahmadu Bello University, Zaria, Nigeria. E-mail: abdulne@gmail.com
}

Submitted: 06 June 2020/Accepted: 10 September 2020

DOI: https://doi.org/10.17532/jhsci.2020.983

UNIVERSITY OF SARAJEVO FACULTY OF HEALTH STUDIES reaction-time, aiming, hand-preference, hand stability, finger-tapping speed, arm stability, and wrist-flexion (2). The importance of the hands in sporting and/or physical activities, most especially that involves catching, lifting, and throwing, is incontestable. Declined handgrip-strength (HGS) is associated with reduced stability, line tracking, firmness, and aiming and tapping abilities (1).

Adolescence is a human developmental phase that is characterized with rapid emotional, physical, 
cognitive, and psychosocial traits, as well as with intense sexual and reproductive maturation (3). Biologically, the social context of family, media, schools, and neighborhoods plays a role in shaping the growth and development of the adolescents $(4,5)$. Adolescence commences with a well-defined, puberty, maturational event, and ends with an imprecise manner $(5,6)$. Chronologically, adolescence age typically ends at age 20, but proficiency in the psychological tasks of adolescence remains into young adulthood $(3,6)$. The phases of adolescence development are subdivided into four segments: Preadolescence (11-13 years), early adolescence (13-15 years), middle adolescence (15-17 years), and late adolescence (17-19 years) $(5,7,8)$.

HGS measurement is a well-established and approved measurement of static strength (9-12). Previous studies have shown that HGS reaches its peak in the fourth decade of life in both genders and then begins to decline thereafter (13). Discrepancies exist in HGS depending on age, sex, and race $(10,11)$; consequently, it is indispensable to generalize standardized reference value (14). HGS is measured for the normal populace in many countries and the normative reference data are dependent on age and sex is used in most clinical practices $(10,11)$. Similarly, male has greater HGS than their female counterparts at all ages (10) and HGS is superior in the right-hand than the left-hand in both gender (15). Several studies have shown that HGS is positively associated with body mass index (BMI) (14,16-21). Previous studies have shown that thin individuals (BMI $<18.5 \mathrm{~kg} \cdot \mathrm{m}^{-2}$ ) have low HGS compared to individuals with a normal BMI $(14,16,17,19,20)$. HGS is positively associated with mineral density in women with natural bone health after menopause $(9,22)$, diagnostic tool for women suffering from osteoporosis $(23,24)$, and used to predict mortality resulting from heart disease and cancer for men (25-27).

HGS is a good health measure for all persons (28-30). Clinically, it is useful in the assessment of rehabilitation (31), evaluation of musculoskeletal function, weakness, and disability (32), and serves as a reliable predictor of subsequent post-operative complications in older female patients $(33,34)$.
Published normative data for HGS of adolescents are available from many countries segregated by age and gender. However, there are no age-based reference data for HGS in relation to BMI in Northern Nigeria. Therefore, the purpose of this study was to establish normative data for right HGS (RHGS) and left HGS (LHGS) and BMI of adolescents between 12 and 20 years in Northern Nigeria; and secondly, to assess the correlation between HGS and BMI.

\section{METHODS}

\section{Research design}

A cross-sectional descriptive study of 1966 adolescents attending public secondary schools in Northern Nigeria was carried out to examine the association of HGS with the BMI.

\section{Sample and sampling procedure}

The minimum sample size for the categorical data was established using the Cochran's sample size formula, at an alpha level of 0.05 and power of $95 \%\left(\mathrm{n}=\mathrm{z}^{2} \mathrm{pq} / \mathrm{d}^{2}\right.$, where; $\mathrm{n}=$ the sample size, $\mathrm{z}=$ standard normal deviate, $\mathrm{p}=$ proportion in the target population expected to have the required characteristics, $q=1-p$ ) (proportion in the target population not having the required characteristics, $\mathrm{d}=$ degree of accuracy required, which was set at 0.05 level) $(35,36)$. The sample size values were achieved based on per 1000 determination (37) (considering 5\% margin of error, 95\% confidence level, in every 1000 population 278 participants were sampled. Therefore, 278 multiplied by $7=$ 1946 participants +20 girls $=1966$ ). Due to the high number of secondary schools in the nine purposively sampled states (out of the 18 northern states of Nigeria), five public secondary schools within the metropolis of two major cities of each state were randomly selected. In each school, participants were selected based on proportional sampling, that is, the number of participants per school $=$ (the entire students within a school $\mathrm{x}$ the size of the sample)/the entire students in a particular state (10 selected schools). At each school, the students were selected from all levels (class 1 - 6). Similarly, the participants selected 
from each class were formed based on the proportional sampling method, that is, the number of participants per class $=($ the entire students in class $\mathrm{x}$ the total selected from the school)/the entire students in the school. School records of birth were used to establish the ages of participants in the study. Participants were randomly selected using a balloting technique. Thus, 2160 participants were expected for the study, but only 1966 participants completed the testing.

\section{Inclusion criteria}

The inclusion criteria for the study were: (a) Age between 12 and 20 years old and (b) healthy and free of illness (i.e., hand pain, osteoarthritis, and rheumatoid arthritis). While, the exclusion criteria include: (a) Age below 12 and those above 20 years old and (b) physical deformity or having ailments.

\section{Ethical considerations}

The study was guided according to the ethical principles of the Declaration of Helsinki, and the ethical guidelines and approval of the Health Research Ethics Committee of the Ahmadu Bello University, Zaria, Nigeria. Permission was obtained from the participating schools and from various Local Governments Education Authorities. Before data collection, the nature and scope of the study were explained to the children and their parents, who gave written informed consent.

\section{Anthropometric measures}

Body mass and height measurements followed the standard procedures as prescribed by Marfell-Jones et al., (38). Body mass was measured to the nearest $0.5 \mathrm{~kg}$, while on a Frankfort position using Seca mass-height Scale, Hamburg, Germany. Height was measured barefooted to the nearest $1.0 \mathrm{~cm}$. BMI was calculated using the formula weight $(\mathrm{kg}) /$ height $\left(\mathrm{m}^{2}\right)$.

\section{Handgrip-strength measurement}

The HGS of the participants was measured while on a Frankfort plane position $(39,40)$ with the arm fully extended and away from the body using Hand Grip Meter 6103, Tanita, Tokyo, Japan. The participants were verbally cheered to generate their maximal HGS. Three trials were given, with 2-4 seconds of maximal contraction and $30 \mathrm{sec}-$ onds rest periods in-between each trial. The contralateral side was then examined according to the same process. The first tested side was random based on the choice of the participant. The results were recorded as kilograms taken from the display of the dynamometer to the nearest $0.1 \mathrm{~kg}$. The display of the dynamometer shows the maximum strength within a trial and the value was reset to zero before each subsequent measurement. HGS was measured thrice for each hand and the best of the three readings was recorded and used for analysis.

\section{Statistical analysis}

The data were cross-checked for normality by means of the Shapiro-Wilk test. For significant disparities in HGS between the LHGS and the RHGS, a paired sample $t$-test was used. Subsequently, two-way ANOVA was computed to ascertain if age and gender have significant effect or interaction on HGS of the participants. Similarly, the Tukey's Honest Significant Difference (HSD) test, is a post-hoc test based on the studentized range distribution, was computed to analyze specifically where the differences lie and the groups' means (compared with each other) are different. A sequence of independent sample $t$-test was also computed to ascertain the disparities between the genders' based on the age group to determine age and gender difference HGS. Similarly, percentiles based on a class interval of five were computed to establish the values for RHGS and LHGS based on the age-group analysis. In addition, the Pearson product-moment correlation (PPMC) was computed to ascertain the correlation between HGS and BMI. All statistical analyses were computed using the IBM-SPSS (version 24) software for Windows.

\section{RESULTS}

One thousand two hundred seventy-five males $(14.7 \pm 1.2$ years; $159.2 \pm 12 \mathrm{~cm} ; 53.3 \pm 13.7 \mathrm{~kg})$ and 691 females $(15.4 \pm 3.6$ years; $154.3 \pm 14 \mathrm{~cm}$; $50.1 \pm 13 \mathrm{~kg}$ ) participated in this study. Shown in 
Table 1 is the descriptive data for height, mass, BMI, and RHGS and LHGS stratified by gender and age. The paired sample $t$-test showed that the RHGS was significantly higher than the LHGS $(t=21.337, p<0.05)$.

The two-way ANOVA show that there was an effect for age in the RHGS $(\mathrm{F}=570.1, p<0.05)$, and in the LHGS $(\mathrm{F}=611.2, p<0.05)$. Post hoc analysis using Tukey's HSD showed that there were significant disparities between all ages in the RHGS and the LHGS $(p<0.05)$; however, the disparities were not significant between participants aged 12 and 14 years (Figure 1).

The two-way ANOVA revealed that the male participants had a significantly greater RHGS $(\mathrm{F}=561.5$, $p<0.05)$ and the LHGS $(\mathrm{F}=621.4, p<0.05)$ compared to the females. Equally, the two-way ANOVA revealed that there was a significant interaction between gender and age for the RHGS $(F=72.2$, $p<0.05)$ and the LHGS ( $\mathrm{F}=92.1, p<0.05)$.

The percentile values for both RHGS and LHGS according to age and gender, as shown in Table 2. Males had significantly higher values of the RHGS than females of the same age $(p<0.0038)$ at $16-20$ years.
Similarly, at ages 15-20 years, males exhibited significantly higher LHGS values than females of the same age $(p<0.0038)$. There was a significant correlation between the BMI and RHGS $(\mathrm{r}=0.480, p<0.01)$ and the LHGS $(r=0.465, p<0.01)$ (Table 3).

\section{DISCUSSION}

The primary purpose of the current study was to establish reference values of the RHGS and LHGS for adolescents in Northern Nigeria and to assess the correlation between the HGS and BMI. There

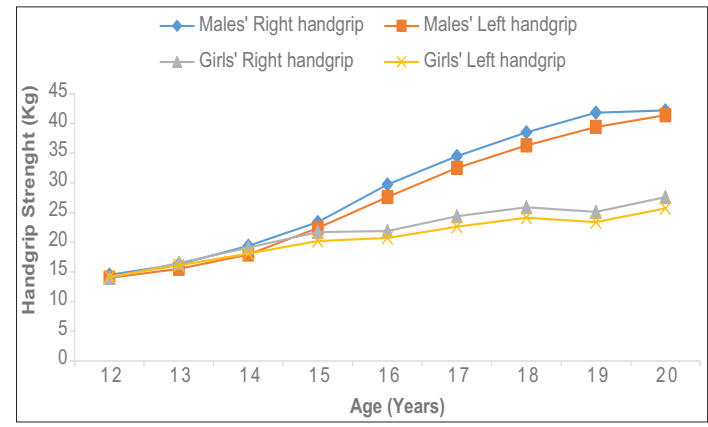

FIGURE 1. Gender and age differences in handgrip strength of the participants.

TABLE 1. Height, body mass, body mass index, right, and left handgrips strength of the participants stratified by gender and age

\begin{tabular}{llcccccc}
\hline Age & G & N & Ht $(\mathrm{cm})$ & BM $(\mathrm{kg})$ & BMl $\left(\mathrm{kg} \cdot \mathrm{m}^{-2}\right)$ & RHGS $(\mathrm{kg})$ & LHGS $(\mathrm{kg})$ \\
\hline $12.0-12.9$ & $\mathrm{M}$ & 174 & $146 \pm 9$ & $36.9 \pm 6.0$ & $17.4 \pm 2.9$ & $14.5 \pm 4.9$ & $14.0 \pm 5.4$ \\
& $\mathrm{~F}$ & 70 & $139 \pm 10$ & $35.0 \pm 8.3$ & $18.0 \pm 2.9$ & $14.0 \pm 5.0$ & $14.2 \pm 4.4$ \\
$13.0-13.9$ & $\mathrm{M}$ & 275 & $143 \pm 7$ & $39.2 \pm 10.2$ & $19.1 \pm 4.1$ & $16.3 \pm 3.8$ & $15.5 \pm 3.6$ \\
& $\mathrm{~F}$ & 98 & $142 \pm 8$ & $36.4 \pm 6.5$ & $18.1 \pm 2.7$ & $16.5 \pm 4.2$ & $16.1 \pm 4.1$ \\
$14.0-14.9$ & $\mathrm{M}$ & 238 & $148 \pm 10$ & $43.6 \pm 12.8$ & $19.7 \pm 4.9$ & $19.4 \pm 7.6$ & $17.9 \pm 4.9$ \\
& $\mathrm{~F}$ & 64 & $147 \pm 9$ & $42.8 \pm 9.6$ & $19.6 \pm 3.5$ & $19.1 \pm 4.2$ & $18.1 \pm 4.1$ \\
$15.0-15.9$ & $\mathrm{M}$ & 190 & $157 \pm 9$ & $50.5 \pm 14.5$ & $20.3 \pm 4.8$ & $23.4 \pm 7.1$ & $22.4 \pm 7.1$ \\
& $\mathrm{~F}$ & 120 & $155 \pm 7$ & $48.7 \pm 10.2$ & $20.2 \pm 3.4$ & $21.7 \pm 5.4$ & $20.2 \pm 5.4$ \\
$16.0-16.9$ & $\mathrm{M}$ & 154 & $164 \pm 8$ & $55.8 \pm 13.5$ & $20.7 \pm 4.0$ & $29.7 \pm 8.8$ & $27.6 \pm 8.2$ \\
& $\mathrm{~F}$ & 91 & $159 \pm 6$ & $54.6 \pm 8.9$ & $21.5 \pm 3.2$ & $21.9 \pm 5.0$ & $20.7 \pm 5.1$ \\
$17.0-17.9$ & $\mathrm{M}$ & 112 & $166 \pm 9$ & $60.0 \pm 14.5$ & $21.5 \pm 4.3$ & $34.5 \pm 9.5$ & $32.5 \pm 7.8$ \\
& $\mathrm{~F}$ & 162 & $161 \pm 6$ & $56.6 \pm 10.4$ & $21.7 \pm 3.5$ & $24.4 \pm 5.3$ & $22.6 \pm 5.1$ \\
$18.0-18.9$ & $\mathrm{M}$ & 52 & $172 \pm 7$ & $63.2 \pm 13.1$ & $21.3 \pm 3.9$ & $38.5 \pm 8.7$ & $36.3 \pm 8.3$ \\
& $\mathrm{~F}$ & 50 & $162 \pm 6$ & $58.8 \pm 11.1$ & $22.5 \pm 4.1$ & $25.9 \pm 5.3$ & $24.1 \pm 5.0$ \\
$19.0-19.9$ & $\mathrm{M}$ & 42 & $171 \pm 9$ & $67.5 \pm 14.7$ & $23.0 \pm 3.9$ & $41.8 \pm 8.2$ & $39.4 \pm 8.1$ \\
& $\mathrm{~F}$ & 24 & $163 \pm 21$ & $59.5 \pm 10.8$ & $22.6 \pm 3.7$ & $25.1 \pm 5.5$ & $23.4 \pm 4.9$ \\
$20.0-20.9$ & M & 38 & $166 \pm 9$ & $63.5 \pm 12.2$ & $22.9 \pm 3.6$ & $42.2 \pm 9.7$ & $41.4 \pm 10.0$ \\
& F & 12 & $161 \pm 5$ & $58.6 \pm 7.9$ & $22.5 \pm 2.8$ & $27.6 \pm 5.9$ & $25.7 \pm 6.0$ \\
\hline
\end{tabular}

M: Male, F: Female, G: Gender, Ht: Height, BM: Body mass, BMl: Body mass index 
TABLE 2. Handgrip strength percentiles of the participants based on gender and age

\begin{tabular}{|c|c|c|c|c|c|c|c|c|c|c|c|c|c|c|c|c|c|c|c|}
\hline \multirow[t]{3}{*}{ Percentiles } & \multirow[t]{3}{*}{ 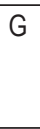 } & \multicolumn{18}{|c|}{ Age (years) } \\
\hline & & \multicolumn{2}{|c|}{$12.0-12.9$} & \multicolumn{2}{|c|}{$13.0-13.9$} & \multicolumn{2}{|c|}{$14.0-14.9$} & \multicolumn{2}{|c|}{$15.0-15.9$} & \multicolumn{2}{|c|}{$16.0-16.9$} & \multicolumn{2}{|c|}{$17.0-17.9$} & \multicolumn{2}{|c|}{$18.0-18.9$} & \multicolumn{2}{|c|}{$19.0-19.9$} & \multicolumn{2}{|c|}{$20.0-20.9$} \\
\hline & & $\mathrm{R}$ & $\mathrm{L}$ & $\mathrm{R}$ & $\mathrm{L}$ & $\mathrm{R}$ & $\mathrm{L}$ & $\mathrm{R}$ & $\mathrm{L}$ & $\mathrm{R}$ & L & $\mathrm{R}$ & L & $\mathrm{R}$ & L & $\mathrm{R}$ & L & $\mathrm{R}$ & L \\
\hline \multirow[t]{2}{*}{95} & M & 22 & 21 & 23 & 22 & 30 & 27 & 37 & 35 & 45 & 41 & 52 & 47 & 53 & 51 & 56 & 53 & 61 & 62 \\
\hline & $F$ & 24 & 22 & 24 & 23 & 27 & 26 & 30 & 30 & 31 & 29 & 33 & 31 & 35 & 32 & 33 & 31 & 38 & 34 \\
\hline \multirow[t]{2}{*}{90} & M & 19 & 19 & 21 & 20 & 27 & 24 & 33 & 32 & 42 & 38 & 45 & 44 & 49 & 47 & 53 & 49 & 58 & 56 \\
\hline & $\mathrm{F}$ & 21 & 20 & 22 & 20 & 26 & 24 & 28 & 26 & 28 & 28 & 31 & 29 & 33 & 31 & 31 & 30 & 36 & 33 \\
\hline \multirow[t]{2}{*}{85} & M & 18 & 18 & 20 & 20 & 24 & 23 & 31 & 30 & 40 & 37 & 42 & 40 & 47 & 45 & 52 & 47 & 53 & 51 \\
\hline & $F$ & 19 & 19 & 20 & 20 & 24 & 22 & 27 & 25 & 27 & 26 & 30 & 28 & 31 & 30 & 30 & 28 & 34 & 32 \\
\hline \multirow[t]{2}{*}{80} & M & 18 & 17 & 20 & 19 & 23 & 22 & 29 & 28 & 37 & 36 & 40 & 37 & 45 & 42 & 48 & 46 & 48 & 49 \\
\hline & $\mathrm{F}$ & 19 & 17 & 19 & 19 & 22 & 22 & 26 & 25 & 26 & 25 & 29 & 27 & 30 & 28 & 30 & 27 & 34 & 31 \\
\hline \multirow[t]{2}{*}{75} & M & 17 & 16 & 19 & 18 & 22 & 21 & 28 & 26 & 35 & 34 & 38 & 36 & 43 & 40 & 47 & 44 & 47 & 47 \\
\hline & $F$ & 18 & 17 & 19 & 18 & 22 & 21 & 26 & 24 & 26 & 24 & 28 & 26 & 29 & 28 & 29 & 27 & 32 & 30 \\
\hline \multirow[t]{2}{*}{70} & M & 16 & 16 & 18 & 17 & 21 & 20 & 26 & 25 & 35 & 33 & 37 & 35 & 43 & 40 & 46 & 44 & 46 & 46 \\
\hline & $F$ & 17 & 16 & 18 & 18 & 21 & 20 & 24 & 22 & 24 & 23 & 27 & 25 & 29 & 27 & 28 & 26 & 31 & 29 \\
\hline \multirow[t]{2}{*}{65} & $M$ & 16 & 15 & 18 & 17 & 20 & 19 & 25 & 24 & 33 & 31 & 36 & 34 & 41 & 39 & 44 & 43 & 45 & 45 \\
\hline & $\mathrm{F}$ & 17 & 16 & 18 & 18 & 20 & 19 & 24 & 22 & 24 & 22 & 26 & 24 & 28 & 26 & 27 & 25 & 30 & 28 \\
\hline 60 & $M$ & 15 & 14 & 17 & 16 & 20 & 19 & 24 & 23 & 32 & 30 & 35 & 33 & 40 & 37 & 44 & 41 & 44 & 44 \\
\hline & $F$ & 16 & 15 & 18 & 17 & 20 & 19 & 23 & 21 & 23 & 22 & 26 & 24 & 27 & 25 & 27 & 25 & 28 & 26 \\
\hline 55 & $M$ & 14 & 14 & 16 & 16 & 19 & 18 & 23 & 22 & 30 & 29 & 34 & 32 & 39 & 36 & 43 & 41 & 43 & 43 \\
\hline & $F$ & 15 & 15 & 17 & 17 & 19 & 18 & 22 & 21 & 22 & & 25 & 23 & 26 & 24 & 26 & 24 & 27 & 25 \\
\hline 50 & $M$ & 14 & 13 & 16 & 15 & 19 & 18 & 22 & 21 & 29 & 27 & 33 & 31 & 38 & 36 & 41 & 40 & 41 & 41 \\
\hline & $F$ & 14 & 14 & 16 & 16 & 18 & 17 & 21 & 18 & 21 & 20 & 24 & 22 & 25 & 23 & 25 & 23 & 26 & 24 \\
\hline 45 & $M$ & 14 & 13 & 16 & 15 & 18 & 17 & 21 & 21 & 28 & 26 & 32 & 31 & 37 & 35 & 41 & 38 & 40 & 40 \\
\hline & $\mathrm{F}$ & 14 & 14 & 16 & 16 & 18 & 17 & 21 & 19 & 21 & 20 & 24 & 22 & 25 & 23 & 25 & 23 & 26 & 24 \\
\hline 40 & $\mathrm{M}$ & 13 & 12 & 15 & 14 & 18 & 16 & 21 & 20 & 27 & 24 & 32 & 30 & 36 & 34 & 40 & 36 & 39 & 39 \\
\hline & $F$ & 13 & 14 & 16 & 16 & 18 & 17 & 20 & 19 & 20 & 19 & 24 & 22 & 25 & 23 & 24 & 22 & 26 & 24 \\
\hline 35 & $M$ & 12 & 12 & 15 & 14 & 17 & 16 & 20 & 19 & 25 & 2 & 31 & 29 & 35 & 33 & 39 & 36 & 39 & 37 \\
\hline & $F$ & 13 & 13 & 15 & 15 & 18 & 17 & 19 & 18 & 19 & 19 & 23 & 21 & 24 & 22 & 23 & 22 & 25 & 23 \\
\hline 30 & $M$ & 12 & 12 & 14 & 14 & 16 & 15 & 19 & 18 & 24 & 22 & 31 & 28 & 34 & 32 & 38 & 34 & 36 & 35 \\
\hline & $F$ & 12 & 11 & 15 & 13 & 17 & 16 & 19 & 18 & 19 & 18 & 22 & 20 & 23 & 22 & 23 & 21 & 24 & 22 \\
\hline 25 & $M$ & 12 & 11 & 14 & 13 & 16 & 15 & 18 & 18 & 23 & 21 & 30 & 27 & 33 & 30 & 37 & 34 & 35 & 34 \\
\hline & $\mathrm{F}$ & 11 & 11 & 14 & 13 & 16 & 16 & 18 & 17 & 18 & 17 & 21 & 19 & 23 & 21 & 22 & 20 & 24 & 22 \\
\hline 20 & $M$ & 11 & 10 & 13 & 13 & 15 & 14 & 17 & 17 & 22 & 20 & 28 & 27 & 32 & 30 & 34 & 32 & 34 & 32 \\
\hline & $\mathrm{F}$ & 11 & 10 & 14 & 12 & 16 & 15 & 18 & 17 & 17 & 16 & 21 & 19 & 22 & 20 & 21 & 19 & 23 & 21 \\
\hline 15 & $\mathrm{M}$ & 10 & 10 & 12 & 12 & 14 & 13 & 16 & 16 & 21 & 18 & 27 & 25 & 30 & 29 & 33 & 31 & 33 & 31 \\
\hline & $\mathrm{F}$ & 10 & 10 & 13 & 12 & 15 & 14 & 16 & 16 & 17 & 15 & 20 & 18 & 21 & 20 & 20 & 18 & 22 & 20 \\
\hline 10 & $M$ & 10 & 9 & 11 & 11 & 13 & 12 & 16 & 15 & 18 & 17 & 25 & 24 & 28 & 27 & 31 & 30 & 31 & 30 \\
\hline & $\mathrm{F}$ & 10 & 9 & 10 & 11 & 14 & 13 & 16 & 14 & 16 & 14 & 18 & 17 & 20 & 18 & 18 & 17 & 20 & 19 \\
\hline 5 & M & 9 & 8 & 10 & 10 & 11 & 10 & 15 & 13 & 16 & 15 & 22 & 22 & 26 & 24 & 28 & 27 & 27 & 27 \\
\hline & $\mathrm{F}$ & 7 & 7 & 9 & 9 & 12 & 11 & 13 & 11 & 14 & 13 & 15 & 14 & 17 & 16 & 16 & 15 & 19 & 17 \\
\hline
\end{tabular}

M: Male, F: Female, G: Gender, L: Left, R: Right

was a significant correlation between HGS of both hands and the BMI. The RHGS was greater than the LHGS in both male and female participants.
The dominance of the RHGS among the participants $(\approx 98 \%)$ is not surprising because most people are generally right-handed in their daily activities. 
TABLE 3. Pearson correlation of body mass index and handgrip strength of the participants

\begin{tabular}{lccc}
\hline & Body mass index & Right handgrip strength & Left handgrip strength \\
\hline Body mass index & 1 & $0.480^{* *}$ & $0.465^{* *}$ \\
Right handgrip strength & $0.480^{\star *}$ & 1 & $0.998^{\star *}$ \\
Left handgrip strength & $0.465^{\star *}$ & $0.998^{\star *}$ & 1 \\
\hline
\end{tabular}

${ }^{* *}$ : Correlation is significant at the 0.01 level (2-tailed)

Consistent with Amaral et al., (41) RHGS was greater than the LHGS in both male and female participants, and the left lateral domination was 8.0\% among the participants. In addition, other studies reported similar findings concerning the gendered dimension of the superiority of the RHGS over LHGS in both male and female participants $(10,11,42,43)$.

In this study, 15-year-old males and older had significantly higher HGS values for both hands than their females' counterparts of similar age groups. This could be attributed to the fact that at the age of 13-15 years, most males begin to develop muscle mass (physique), unlike their female counterparts. Previous studies have reported disparities in HGS among males and females at the age of 12 and 13 years $(44,45)$. While males at the age of 12 and 13 years begin to develop heavier bones; more muscle mass and advanced hemoglobin levels than their female counterpart as a result of testosterone secretion (45), the females develop a broader pelvis, more fats, and an enlargement in breast size as a result of estrogen secretion (44). Similar findings were reported by other researchers $(10,11,41-43)$. A recent study reports the superiority of male dominance in both the RHGS and the LHGS compared to the female (41).

The present study revealed age and gender differences in HGS; however, there was no significant difference in the HGS of both genders at ages 16 and 17 years. It is plausible that males and females tend to develop more muscle mass at this stage, thus, more muscle strength at the adolescence age which is characterized by significant growth and development, particularly at the start of the adolescent years and afterward. Several studies have attested to the biological age synchronization of HGS in both genders with advancing age. For example, one study revealed that older adolescents aged 17-19 years exhibited superior HGS values than their younger at aged 14-16 years in both males and females (42). Similarly, another study indicates that HGS improves with age for both genders (46). An earlier study revealed a decline in HGS at the age of 30 years for men and 50 years for women (43). However, one study indicated that HGS attains peak at 35-39 years, and afterward decreases in both sexes, and HGS significantly correlated with height, weight, and BMI (10).

\section{Limitations}

The most obvious limitation of this study is that it presents the values as reference-ranges for the $\mathrm{LH}$ and RH's instead of dominant and non-dominant hands, respectively. The cross-sectional nature of the study limits ascertaining a causal relationship in the HGS among the participants. Moreover, the results of this study cannot be generalized to the entire Northern region in Nigeria because most of the areas were inaccessible at the time of data collection due to insecurity (communal crisis and insurgency). Similarly, as a result of poor girl-child enrolment in the region, the ratio of male and female was disproportionate up to 1.85 , which may cause normative norm deviations in the results.

\section{CONCLUSION}

There are gender and age variations in the HGS of adolescents in Northern Nigeria. The HGS values provided in this present study will serve as a reference for HGS among adolescent students with healthy upper limbs in Northern Nigeria and might be possibly used in clinical settings and rehabilitation programs for adolescents within the age ranges. In addition, the handgrip normative data would aid in assessing the handgrip, upper body, and overall strengths of adolescents. The present study confirmed the direct correlation of HGS with BMI of the participants. Future studies should conduct 
a population-based study involving children and adolescents in other parts of the country to establish normative HGS values of children and adolescents in Nigeria.

\section{ACKNOWLEDGMENTS}

Not applicable.

\section{FUNDING}

Not applicable.

\section{COMPETING INTERESTS}

The authors declare that they have no competing interests.

\section{REFERENCES}

1. Martin JA, Ramsay J, Hughes C, Peters DM, Edwards MG. Age and grip strength predict hand dexterity in adults. PLoS One 2015;10(2):1-18.

https://doi.org/10.1371/journal.pone.0117598.

2. Bobos P. Evaluating Factors that Affect Hand Dexterity After Distal Radius Fracture, Electronic Thesis and Dissertation Repository. 4258. Ontario: The University of Western Ontario; 2016.

3. Lassi ZS, Mansoor T, Salam RA, Bhutta SZ, Das JK, Bhutta ZA. Review of nutrition guidelines relevant for adolescents in low and middle income countries. Ann N Y Acad Sci 2017;1393(1):51-60.

https://doi.org/10.1111/nyas.13332

4. Patton GC, Sawyer SM, Santelli JS, Ross DA, Afifi R, Allen NB, et al. Our future: A Lancet commission on adolescent health and wellbeing. Lancet 2016;387(10036):2423-78.

5. Sawyer SM, Afifi RA, Bearinger LH, Blakemore SJ, Dick B, Ezeh $A C$, et al. Adolescence: A foundation for future health. Lancet 2012;379(9826):1630-40.

https://doi.org/10.1016/s0140-6736(12)60072-5.

6. Ortega G, Morgan G. Comparing child and adult development of a visual phonological system. LIA. 2010;1(1):67-81.

7. Goodway JD, Ozmun JC, Gallahue DL. Understanding Motor Development: Infants, Children, Adolescents, Adults. $8^{\text {th }}$ ed. Burlington: Jones \& Bartlett Learning; 2019. p. 415.

8. Mertens DM, Wilson AT. Program Evaluation Theory and Practice. $2^{\text {nd }}$ ed. New York: Guilford Publications; 2018. p. 620.

9. Barrea L, Muscogiuri G, Di Somma C, Tramontano G, De Luca V, Illario M, et al. Association between Mediterranean diet and hand grip strength in older adult women. Clin Nutr 2019;38(2):721-9.

https://doi.org/10.1016/j.clnu.2018.03.012.

10. Kim CR, Jeon YJ, Kim MC, Jeong T, Koo WR. Reference values for hand grip strength in the South Korean population. PLoS One. 2018;13(4):1-12. https://doi.org/10.1371/journal.pone.0195485.

11. Massy-Westropp NM, Gill TK, Taylor AW, Bohannon RW, Hill CL. Hand grip strength: Age and gender stratified normative data in a population-based study. BMC Res Notes. 2011;4(127):1-5.

https://doi.org/10.1186/1756-0500-4-127.

12. Sousa-Santos A, Amaral T. Differences in handgrip strength protocols to identify sarcopenia and frailty-a systematic review. BMC Geriatr 2017;17(238):1-21.

https://doi.org/10.1186/s12877-017-0625-y.

13. Angst F, Drerup S, Werle S, Herren DB, Simmen BR, Goldhahn J. Prediction of grip and key pinch strength in 978 healthy subjects. BMC Musculoskelet Disord 2010;11(94):1-6.

https://doi.org/10.1186/1471-2474-11-94.

14. Hamasaki H, Kawashima $Y$, Katsuyama H, Sako A, Goto A, Yanai H. Association of handgrip strength with hospitalization, cardiovascular events, and mortality in Japanese patients with Type 2 diabetes. Sci Rep 2017;7(1):1-9.

https://doi.org/10.1038/s41598-017-07438-8.

15. Wong SL, Coates AL, To T. Exposure to industrial air pollutant emissions and lung function in children: Canadian health measures survey, 2007 to 2011. Health Rep 2016;27(2):3-10.

16. Alahmari KA, Silvian SP, Reddy RS, Kakaraparthi VN, Ahmad I, Alam MM. Hand grip strength determination for healthy males in Saudi Arabia: A study of the relationship with age, body mass index, hand length and forearm circumference using a hand-held dynamometer. J Int Med Res 2017;45(2):540-8.

https://doi.org/10.1177/0300060516688976.

17. Aparicio VA, Ruiz-Cabello P, Borges-Cosic M, Andrade A, Coll-Risco I, Acosta-Manzano P, et al. Association of physical fitness, body composition, cardiometabolic markers and adherence to the Mediterranean diet with bone mineral density in perimenopausal women. The FLAMENCO project. J Sports Sci 2017;35(9):880-7.

https://doi.org/10.1080/02640414.2016.1196825.

18. Cadenas-Sanchez C, Vanhelst J, Ruiz JR, Castillo-Gualda R, Libuda L, Labayen $\mathrm{I}$, et al. Fitness and fatness in relation with attention capacity in European adolescents: The HELENA study. J Sci Med Sport 2017;20(4):373-9.

https://doi.org/10.1016/j.jsams.2016.08.003.

19. Ji C, Zheng L, Zhang R, Wu Q, Zhao Y. Handgrip strength is positively related to blood pressure and hypertension risk: Results from the national health and nutrition examination survey. Lipids Health Dis 2018;17(1):1-7. https://doi.org/10.1186/s12944-018-0734-4.

20. Riviati N, Setiati S, Laksmi PW, Abdullah M. Factors related with handgrip strength in elderly patients. Indones J Intern Med. 2017;49(3):215-9.

21. Smith MP, Standl M, Berdel D, von Berg A, Bauer CP, Schikowski T, et al. Handgrip strength is associated with improved spirometry in adolescents. PLoS One. 2018;13(4):1-14. https://doi.org/10.1371/journal.pone.0194560.

22. Ibeneme S, Ezeigwe C, Ibeneme GC, Ezuma A, Okoye I, Nwankwo JM. Response of gait output and handgrip strength to changes in body fat mass in pre-and postmenopausal women. Curr Ther Res Clin Exp 2019;90:92-8. https://doi.org/10.1016/j.curtheres.2017.03.005.

23. Li YZ, Zhuang HF, Cai SQ, Lin CK, Wang PW, Yan LS, et al. Low grip strength is a strong risk factor of osteoporosis in postmenopausal women. Orthop Surg 2018;10(1):17-22.

https://doi.org/10.1111/os.12360.

24. Yoshimura N, Muraki S, Oka H, lidaka T, Kodama R, Kawaguchi $H$, et al. Is osteoporosis a predictor for future sarcopenia or vice versa? Fouryear observations between the second and third ROAD study surveys. Osteoporos Int 2017;28(1):189-99.

https://doi.org/10.1007/s00198-016-3823-0.

25. Belarmino G, Gonzalez MC, Sala P, Torrinhas RS, Andraus W, D'Albuquerque LA, et al. Diagnosing sarcopenia in male patients with cirrhosis by dual energy X-ray absorptiometry estimates of appendicular skeletal muscle mass. JPEN J Parenter Enteral Nutr 2018;42(1):24-36.

https://doi.org/10.1177/0148607117701400. 
26. Larcher B, Zanolin-Purin D, VonbankA, Heinzle CF, Mader A, Sternbauer S, et al. Usefulness of handgrip strength to predict mortality in patients with coronary artery disease. Am J Cardiol 2020;129:5-9.

https://doi.org/10.1016/j.amjcard.2020.05.006.

27. Rodrigues J, Santin F, Dos Santos Barbosa Brito F, Lindholm B, Stenvinkel $P$, Avesani CM. Nutritional status of older patients on hemodialysis: Which nutritional markers can best predict clinical outcomes? Nutrition. 2019;65:113-9.

https://doi.org/10.1016/j.nut.2019.03.002.

28. Shin IH, Kim DK, Seo KM, Kang SH, Lee SY, Son S. Relation between respiratory muscle strength and skeletal muscle mass and hand grip strength in the healthy elderly. Ann Rehabil Med 2017;41(4):686. https://doi.org/10.5535/arm.2017.41.4.686.

29. McGrath RP, Kraemer WJ, Al Snih S, Peterson MD. Handgrip strength and health in aging adults. Sports Med 2018;48(9):1993-2000. https://doi.org/10.1007/s40279-018-0952-y.

30. Plys $E$, Desrichard O. Associations between positive and negative affect and the way people perceive their health goals. Front Psychol 2020;11:334. https://doi.org/10.3389/fpsyg.2020.00334.

31. Abdou M. Usefulness of upper and lower limb muscles strength in the evaluation of clinical severity of heart failure in elderly patients. World $\mathrm{J}$ Cardiovasc Dis 2019;9(5):370-83. https://doi.org/10.4236/wjcd.2019.95033.

32. Bohannon RW, Magasi S. Identification of dynapenia in older adults through the use of grip strength T-scores. Muscle Nerve 2015;51(1):102-5. https://doi.org/10.1002/mus.24264.

33. Tomás M, Galán-MercantA, Fernandes B. Body composition changes over three years in older adults: A descriptive longitudinal analysis. In: The $10^{\text {th }}$ International Conference on Cachexia, Sarcopenia and Muscle Wasting. Rome, Italy: Wiley Online Library; 2017.

34. Yin L, Lin X, Li N, Zhang M, He X, Liu J, et al. Evaluation of the global leadership initiative on malnutrition criteria using different muscle mass indices for diagnosing malnutrition and predicting survival in lung cancer patients. JPEN J Parenter Enteral Nutr [published online ahead of print, 2020 May 9] 2020;

https://doi.org/10.1002/jpen.1873

35. Islam MR. Sample size and its role in central limit theorem (CLT). Int J Phys Mathe 2018;1(1):37-47.

https://doi.org/10.31295/ijpm.v1n1.42.

36. Kroonenberg P, Verbeek A. The tale of Cochran's rule: My contingency table has so many expected values smaller than 5 , what am I to do? Am
Stat 2018;72(2):175-83.

https://doi.org/10.1080/00031305.2017.1286260.

37. Kim JK, Wang Z. Sampling techniques for big data analysis. Int Stat Rev 2019;87:S177-91.

38. Marfell-Jones M, Stewart A, de Ridder J. International Society for the Advancement of Kinanthropometry. Wellington, New Zealand 2012. https://doi.org/10.4324/9780203970157.

39. Amirabdollahian F, Haghighatdoost F. Anthropometric indicators of adiposity related to body weight and body shape as cardiometabolic risk predictors in british young adults: Superiority of waist-to-height ratio. J Obesity 2018;2018:15.

https://doi.org/10.1155/2018/8370304.

40. Booysen MJ, Gradidge PJ, Constantinou D. Anthropometric and motor characteristics of South African national level female soccer players. J Hum Kinet 2019;66(1):121-9.

https://doi.org/10.1515/hukin-2017-0189.

41. Amaral CA, Amaral TL, Monteiro GT, Vasconcellos MT, Portela MC. Hand grip strength: Reference values for adults and elderly people of Rio Branco, Acre, Brazil. PLoS One 2019;14(1):1-13.

https://doi.org/10.1371/journal.pone.0211452

42. Silva DA, Pelegrini A, de Castro JA, de Lima TR, de Sousa GR, de Lima Silva JM, et al. Low handgrip strength levels among adolescents in a city in southern Brazil. J Bodyw Mov Ther 2017;21(4):884-9.

https://doi.org/10.1016/j.jbmt.2017.03.004.

43. Vianna LC, Oliveira RB, Araújo CG. Age-related decline in handgrip strength differs according to gender. J Strength Cond Res 2007;21(4):1310-4. https://doi.org/10.1519/r-23156.1.

44. Sawyer SM, Azzopardi PS, Wickremarathne D, Patton GC. The age of adolescence. Lancet Child Adolesc Health 2018;2(3):223-8.

https://doi.org/10.1016/s2352-4642(18)30022-1.

45. Simmonds DJ, Hallquist MN, Asato M, Luna B. Developmental stages and sex differences of white matter and behavioral development through adolescence: A longitudinal diffusion tensor imaging (DTI) study. Neuroimage 2014;15(92):356-68.

https://doi.org/10.1016/j.neuroimage.2013.12.044.

46. Gómez-Campos R, Andruske CL, Arruda MD, Sulla-Torres J, PachecoCarrillo J, Urra-Albornoz C, et al. Normative data for handgrip strength in children and adolescents in the Maule region, Chile: Evaluation based on chronological and biological age. PLoS One. 2018;13(8):1-13.

https://doi.org/10.1371/journal.pone.0201033. 